\title{
PERANCANGAN SISTEM INFORMASI PENJUALAN PERLENGKAPAN RUMAH TANGGA BERBASIS WEB DI PT. TEGAR PRIMA NUSANTARA CIMAHI
}

\author{
Johnson Sihombing ${ }^{1}$, Lamhot Sihotang ${ }^{2}$ \\ Manajemen Informatika ${ }^{1,2}$ \\ Politeknik Piksi Ganesha Bandung \\ Jl. Jend. Gatot Subroto No. 301 Bandung 40274 \\ John97.sihombing@gmail.com ${ }^{1}$, boris_olivia@yahoo.co.id ${ }^{2}$
}

\begin{abstract}
Abstrak
Berkembang pesatnya bidang teknologi khususnya teknologi informasi, semakin dirasakan manfaatnya dewasa ini dalam berbagai sektor termasuk sektor bisnis.

PT. Tegar Primanusantara yang berlokasi di Cimahi merupakan suatu perusahaan bisnis untuk produk-produk tekstil dan garmen. Dalam menjalankan kegiatan penjualan produk, perusahaan tersebut masih menggunakan cara manual dalam pengolahan datanya dan belum menggunakan salah satu aplikasi teknologi berbasis web yaitu e-commerce untuk strategi pemasaran produk. Dengan cara tersebut, maka akan memunculkan kendala-kendala yang cukup merepotkan bagi pihak perusahaan, seperti : zona pemasaran yang tidak dapat menjangkau seluruh kawasan dan masyarakat tidak dapat menerima informasi dengan cepat dan akurat tentang produk-produk baru yang dihasilkan perusahaan.
\end{abstract}

Penelitian yang dilakukan penulis bertujuan untuk merancang bangun sebuah sistem informasi penjualan perlengkapan rumah tangga yang berbasis website di perusahaan tersebut, sehingga nantinya diharapkan dapat menjangkau daerah pemasaran yang luas dan mempermudah pelanggn dalam bertransaksi atau memesan produk.

Metode perancangan sistem informasi penjualan berbasis web ini adalah dengan menggunakana metode UML (Unified Modelling Language), dan untuk implementasi menggunakan bahasa pemograman PHP. Adapun database yang digunakan adalah MySQL sebagai DBMS (Data Base Management System), yang merupakan antarmuka dari aplikasi yang dihasilkan. Melalui penggunaan teknologi internet, maka layanan produk dapat dilakukan secara komprehensif serta tidak memiliki ruang batas dan waktu. Adapun hasil penelitian yang dilakukan penulis adalah membuat sistem penjualan perlengkapam rumah tangga berbasis web pada PT. Tegar Primanusantara, yang berpengaruh terhadap proses bisnis menjadi lebih mudah.

\section{Kata kunci :}

Sistem Informasi, Penjualan, PHP, MySQL.

\begin{abstract}
The rapid development of technology, especially information technology, is increasingly being felt today in various sectors including the business sector.

PT. Tegar Primanusantara located in Cimahi is a business company for textile and garment products. In carrying out product sales activities, the company still uses manual methods in processing data and has not used one of the web-based technology applications, $e$ commerce for product marketing strategies. In this way, it will create constraints that are quite inconvenient for the company, such as: marketing zones that cannot reach the entire region and the public cannot receive information quickly and accurately about new products produced by the company.
\end{abstract}

The research conducted by the author aims to design and build a website-based information system for selling household appliances at the company, so that later it is expected to be able to reach a wide 
marketing area and make it easier for customers to transact or order products.

The method of designing a web-based sales information system is to use the UML (Unified Modeling Language) method, and for implementation using the PHP programming language. The database used is MySQL as a DBMS (Data Base Management System), which is the interface of the resulting application. Through the use of internet technology, product services can be achieved done comprehensively and do not have a limit and time space. The results of research conducted by the author is to create a web-based household equipment sales system at PT. Tegar Primanusantara, which influences business processes, becomes easier.

Keywords:

Information Systems, Sales, PHP, MySQL.

\section{Pendahuluan}

\section{I.1 Latar Belakang}

Media informasi online dengan berbagai bentuk dan fungsinya yang telah menyebar ke seluruh bidang kehidupan saat ini merupakan salah satu dampak dari penggunaan internet yang telah menjadi jaringan dan komunikasi global di seluruh dunia. Internet pun dapat digunakan sebagai media komunikasi di bidang bisnis dalam sebuah perusahaan. Selain mampu menyajikan informasi yang cepat dan akurat, perusahaan akan lebih mudah menginformasikan produk dan jasanya kepada masyarakat melalui pemanfaatan teknologi internet. Internet mampu menyimpan data dalam jumlah kapsitas yang sangat besar serta dapat disebarkan (sharing). Hal tersebut mempermudah interaksi manusia dengan dunia global tanpa ada batas ruang dan waktu.

Salah satu aplikasi internet yang banyak digunakan pada bidang bisnis saat ini adalah aplikasi electronic commerce (e-commerce). Dengan adanya e-commerce, maka mempermudah suatu perusahaan untuk melakukan transaksi pemesanan produk oleh pelanggan, penjualan produk hingga pemasaran produk.

Sehubungan hal tersebut di atas, penulis melakukan penelitian tentang penjualan yang berbasis internet di PT Tegar Primanusantara yang beralamat di Jl. Industri I No.3 RT 01 RW 08 Leuwigajah Cimahi.
Proses penjualannya yaitu mengandalkan Distributor dibawah naungan Dialogue Management Group (DMG), dimana produk yang dihasilkan dengan brand Dialogue, Snobby, Makarios. Selain mengandalkan Distributor perusahaan ini juga melakukan kegiatan penjualan produk ke berbagai wilayah di Indonesia dengan sistem mengirimkan beberapa orang Salesman.

Kegiatan penjualan di PT Tegar Primanusantara pada saat ini masih dilakukan secara manual, yaitu ketika konsumen ingin memesan produk. Para konsumen (Toko Grosiran, Semi Grosir, dan Modern Market) masih harus menunggu Salesman datang untuk menawarkan produk tersebut atau memesan ulang. Pengiriman informasi masih melalui SMS dan telpon, sehingga menjadikan suatu kendala bagi pihak perusahaan, karena bentuk pemesanan produk yang di inginkan oleh pelanggan tidak selaras (sinkron) pada saat order pemesanan diterima oleh pihak perusahaan. Hal ini tentu saja akan membuat pelanggan untuk melakukan order pemesanan produk lagi yang secara otomatis membutuhkan waktu cukup lama.

\section{I.2 Tujuan Penelitian}

Adapun tujuan yang dilaksanakan penulis pada penelitian ini adalah sebagai berikut :

1. Merancang bangun sistem informasi penjualan perlengkapan rumah tangga berbasis web pada PT Tegar Primanusantara Cimahi.

2. Menyajikan informasi kepad pelanggan berupa : kategori produk, harga serta info lainnya yang berkaitan produk perusahaan.

3. Mempermudah PT Tegar Primanusantara dalam pengolahan data penjualan khususnya penjualan online.

4. Membuat laporan rekapitulasi penjulan secara harian dan periodik.

\section{KAJIAN LITERATUR}

\section{II.1 Pengertian Penjualan}

Yang menyatakan bahwa "selling" melakukan penjualan ialah suatu kegiatan yang ditujukan untuk mencari pembeli, mempengaruhi dan memberikan petunjuk agar pembeli dapat menyesuaikan kebutuhannnya dengan produk yang ditawarkan serta mengadakan perjanjian mengenai harga yang 
menguntungkan bagi kedua belah pihak ("Moekijat Dalam Buku Kamus Istilah Ekonomi 2000:488”).

Ronny A. Rusli dan Hendra menerjemahkan dalam buku "Manajemen Pemasaran" pengertian penjualan ialah "penjualan ialah proses sosial manajerial dimana individu dan kelompok mendapatkan apa yang mereka butuhkan dan inginkan, menciptakan, menawarkan dan mempertukarkan produk yang bernilai dengan pihak lain, (Philip Kotler 2000:8”).

"Penjualan ialah sebagai kegiatan manusia yang mengarahkan untuk memenuhi dan memuaskan kebutuhan dan keinginan melalui proses pertukaran" (Assuari “2004:5”).

"Penjualan kredit ialah penjualan yang dilakukan bilamana pembayaran baru diterima beberapa waktu kemudian: (Haryono “2003:327”).

Menyatakan bahwa, dalam transaksi penjualan kredit, jika order dari pelanggan telah dipenuhi dengan pengiriman barang atau penyerahan jasa, untuk jangka waktu tertentu perusahaan memiliki piutang kepada pelanggannya (Mulyadi “1997:204”).

\section{II.2 Jenis-Jenis Penjualan}

Adapun jenis-jenis penjualan yang diantaranya yaitu :

\section{Trade Selling}

Jenis penjualan anatara pedagang kepada pedagang grosir atau eceran.

\section{Tehnical Selling}

Suatu metode/teknik dimana pedagang memberi informasi berupa masukan dan saran-saran apa saja yang harus dilakukan oleh pembeli agar volume penjualan barang semakin meningkat.

\section{Missionary Selling}

Usaha-usaha yang dilakukan perusahaan agar konsumen membeli produk atau jasa yang tersedia di perusahaan dalam rangka meningkatkan volume penjualan perusahaan

\section{New Business Selling}

Merupakan suatu usaha-usaha untuk membuka transaksi batu dengan cara mengubah seorang calon konsumen menjadi konsumen.

\section{II.3 Tujuan Penjualan}

Dari sejumlah pengeritan tentang penjualan diatas, maka dapat disimpukan bahwa tujuan dari penjualan dalam suatu perusahaan adalah mendapatkan keuntungan atau laba yang sebesarbesarnya dari hasil penjualan produk atau jasa yang ada di perusahan. Hal tersebut dapat direalisasikan jika proses penjualan berjalan lancar sesuai perencanaan. Adapun tujuan utama perusahaan dalam penjualan produk atau jasanya adalah : meraih nilai penjualan, mendatangkan keuntungan dan mendukung pertumbuhan perusahaan.

\section{II.4 Faktor-faktor yang mempengeruhi penjualan}

Dibawah ini dapat dilihat factor-faktor apa saja yang dapat mempengaruhi penjualan :

1. Kondisi dan Kemampuan Penjual

Suatu metode yang digunakan penjual agar target penjualan sesuai dengan yang diharapkan, dengan cara meyakinkan sedemikian rupa kepada pembeli untuk membeli produk atau jasanya.

\section{Kondisi Pasar}

Faktor Kondisi Adapun yang dimaksud antara lain : jenis pasar, segmen pasar, daya beli, frekuensi pembelian serta keinginan dan kebutuhan

3. Modal

Kebutuhan akan sarana dan usaha-usaha yang berkaitan dengan kegiatan penjualan, seperti armada transportasi, event promosi produk, lokasi pameran produk.

\section{Faktor lain}

Dibutuhkan dana yang tidak sedikit untuk kegiatan-kegiatan dibawah ini yang terkait dengan faktor yag mempengaruhi penjualan, seperti : iklan produk, peragaan, dan bonus kepada pembeli.

\section{II.4 Penelitian Terkait}

Penelitian-penelitian terkait dalam hal perancangan sistem informasi penjualan berbasis online dapat dilihat dibawah ini : 
Tabel 1 Penelitian Terkait

\begin{tabular}{|c|c|c|c|c|c|}
\hline 0 & $\begin{array}{l}\text { Penul } \\
\text { is }\end{array}$ & $\begin{array}{l}\text { Ta } \\
\text { hu } \\
\text { n }\end{array}$ & $\begin{array}{l}\text { Publ } \\
\text { ikasi }\end{array}$ & Judul & Hasil \\
\hline \multirow[b]{2}{*}{1} & \multirow{2}{*}{$\begin{array}{l}\text { Yusne } \\
\text { ni } \\
\text { Febria } \\
\text { ni, } \\
\text { Fitra } \\
\text { Nur } \\
\text { Haki } \\
\text { m, } \\
\text { Achm } \\
\text { ad } \\
\text { Solec } \\
\text { han }\end{array}$} & \multirow[b]{2}{*}{$\begin{array}{l}20 \\
18\end{array}$} & \multirow{2}{*}{$\begin{array}{l}\text { Jurn } \\
\text { al } \\
\text { SIS } \\
\text { TEC } \\
\text { H, } \\
\text { vol } \\
1, \\
\text { No } \\
2, \\
\text { Dese } \\
\text { mbe } \\
\text { r } \\
2018\end{array}$} & \multirow{2}{*}{$\begin{array}{l}\text { Penge } \\
\text { mbang } \\
\text { an } \\
\text { Sistem } \\
\text { Inform } \\
\text { asi } \\
\text { Penjual } \\
\text { an, } \\
\text { Pembel } \\
\text { ian dan } \\
\text { Persedi } \\
\text { aan } \\
\text { Berbasi } \\
\text { s Web }\end{array}$} & $\begin{array}{l}\text { Adanya } \\
\text { kemudahan } \\
\text { yang } \\
\text { diberikan } \\
\text { kepada } \\
\text { Adminisrat } \\
\text { or dalam } \\
\text { membuat } \\
\text { laporan } \\
\text { rekapitulasi } \\
\text { penjualan. } \\
\end{array}$ \\
\hline & & & & & \begin{tabular}{l}
\multicolumn{1}{c}{ Adnin } \\
dapat \\
mengetahui \\
informasi \\
produk data \\
penjualan \\
dengan \\
mudah \\
dengan \\
menggunak \\
an koneksi \\
internet.
\end{tabular} \\
\hline
\end{tabular}

Kesimpulan : Implementasi sistem membuat admin dapat mengecek, mengelola dan membuat laporan beserta data penjualan dengan mudah. Penerapn sistem membuat proses penjualan dilakukan dengan lebih mudah

\begin{tabular}{|c|c|c|c|c|c|}
\hline No & $\begin{array}{l}\text { Penul } \\
\text { is }\end{array}$ & $\begin{array}{l}\text { Ta } \\
\text { hu } \\
\text { n }\end{array}$ & $\begin{array}{l}\text { Publ } \\
\text { ikasi }\end{array}$ & Judul & Hasil \\
\hline \multirow[b]{2}{*}{2} & \multirow{2}{*}{$\begin{array}{l}\text { Yusne } \\
\text { ni } \\
\text { Febria } \\
\text { ni, } \\
\text { Fitra } \\
\text { Nur } \\
\text { Haki } \\
\text { m, } \\
\text { Achm } \\
\text { ad } \\
\text { Solec } \\
\text { han }\end{array}$} & \multirow[b]{2}{*}{$\begin{array}{l}20 \\
18\end{array}$} & \multirow{2}{*}{$\begin{array}{l}\text { Jurn } \\
\text { al } \\
\text { SIS } \\
\text { TEC } \\
\text { H, } \\
\text { vol } \\
1, \\
\text { No } \\
2, \\
\text { Dese } \\
\text { mbe } \\
\text { r } \\
2018\end{array}$} & \multirow{2}{*}{$\begin{array}{l}\text { Penge } \\
\text { mbang } \\
\text { an } \\
\text { Sistem } \\
\text { Inform } \\
\text { asi } \\
\text { Penjual } \\
\text { an, } \\
\text { Pembel } \\
\text { ian dan } \\
\text { Persedi } \\
\text { aan } \\
\text { Berbasi } \\
\text { s Web }\end{array}$} & $\begin{array}{l}\text { Adanya } \\
\text { kemudahan } \\
\text { yang } \\
\text { diberikan } \\
\text { kepada } \\
\text { Adminisrat } \\
\text { or dalam } \\
\text { membuat } \\
\text { laporan } \\
\text { rekapitulasi } \\
\text { penjualan. }\end{array}$ \\
\hline & & & & & \begin{tabular}{l}
\multicolumn{1}{c}{ Adnin } \\
dapat \\
mengetahui \\
informasi \\
produk data \\
penjualan \\
dengan \\
mudah \\
dengan \\
menggunak \\
an koneksi \\
internet.
\end{tabular} \\
\hline
\end{tabular}

membuat proses penjualan dilakukan dengan lebih mudah

\begin{tabular}{|c|c|c|c|c|c|}
\hline No & $\begin{array}{l}\text { Penul } \\
\text { is }\end{array}$ & $\begin{array}{l}\text { Ta } \\
\text { hu } \\
\text { n }\end{array}$ & $\begin{array}{l}\text { Publ } \\
\text { ikasi }\end{array}$ & Judul & Hasil \\
\hline 3 & $\begin{array}{l}\text { Farha } \\
\mathrm{n} \\
\text { Rama } \\
\text { dhan, } \\
\text { Nurai } \\
\text { ni } \\
\text { Purwa } \\
\text { ndari }\end{array}$ & $\begin{array}{l}20 \\
18\end{array}$ & $\begin{array}{l}\text { Kalb } \\
\text { i } \\
\text { Scie } \\
\text { ntia, } \\
\text { Volu } \\
\text { me } \\
5, \\
\text { Nom } \\
\text { or } 1 \text {, } \\
\text { Febr } \\
\text { uari } \\
2018\end{array}$ & $\begin{array}{l}\text { Sistem } \\
\text { Inform } \\
\text { asi } \\
\text { Penjual } \\
\text { an } \\
\text { Berbasi } \\
\text { s Web } \\
\text { Pada } \\
\text { PT. } \\
\text { Mustik } \\
\text { a Jati }\end{array}$ & $\begin{array}{l}\text { Tahap } \\
\text { Implementa } \\
\text { si Sistem } \\
\text { Informasi } \\
\text { Penjualan } \\
\text { di PT. PT. } \\
\text { Mustika } \\
\text { Jati } \\
\text { berbasis } \\
\text { web } \\
\text { mengasilka } \\
\text { n Tampilan } \\
\text { halaman } \\
\text { login, } \\
\text { halaman } \\
\text { kasir, } \\
\text { halaman } \\
\text { komisaris } \\
\text { dan } \\
\text { halaman } \\
\text { laporan }\end{array}$ \\
\hline
\end{tabular}

Kesimpulan :

Pene:litian ini menghasilkan Sistem Informasi Penjualan berbasis web yang berguna sebagai alat bantu perusahaan untuk mencatat, menyimpan, mengolah, dan mengintegrasi data di PT. Mustika Jati.

Sistem yang dibangun mampu memberikan informasi lengkap mengenai penjualan, stok barang, dan pelanggan. Sehingga yang telah dibangun menjadi sebuah alat bantu perusahaan dalam melakukan kegiatan penjualan. Fungsi dari sistem dapat berkerja sesuai pengujian yang telah dilakukan oleh pengguna melalui metode black box testing.

\begin{tabular}{|c|c|c|c|c|c|}
\hline No & $\begin{array}{l}\text { Penul } \\
\text { is }\end{array}$ & $\begin{array}{c}\text { Ta } \\
\text { hu } \\
\text { n }\end{array}$ & $\begin{array}{l}\text { Publ } \\
\text { ikasi }\end{array}$ & Judul & Hasil \\
\hline $\bar{~} 4$ & $\begin{array}{l}\text { Farha } \\
\mathrm{n} \\
\text { Rama } \\
\text { dhan, } \\
\text { Nurai } \\
\text { ni } \\
\text { Purwa } \\
\text { ndari }\end{array}$ & $\begin{array}{l}20 \\
15\end{array}$ & $\begin{array}{l}\text { Jurn } \\
\text { al } \\
\text { TA } \\
\text { M } \\
\text { (Tec } \\
\text { hnol } \\
\text { ogy } \\
\text { Acc } \\
\text { epta } \\
\text { nce } \\
\text { Mod } \\
\text { el) } \\
\text { Volu } \\
\text { me } 4 \\
\text { Juli } \\
2015\end{array}$ & $\begin{array}{l}\text { Sistem } \\
\text { Inform } \\
\text { asi } \\
\text { Penjual } \\
\text { an } \\
\text { Produk } \\
\text { Berbasi } \\
\text { s Web } \\
\text { Pada } \\
\text { Chaeel } \\
\text { Distro } \\
\text { Pringse } \\
\text { wu }\end{array}$ & $\begin{array}{l}\text { memudahh } \\
\text { an } \\
\text { masyarakat } \\
\text { untuk } \\
\text { memilih } \\
\text { pakaian } \\
\text { yang } \\
\text { diinginkan } \\
\text { dan } \\
\text { bertambah } \\
\text { luasnya } \\
\text { area } \\
\text { promosi } \\
\text { dan } \\
\text { pemasaran } \\
\text { pakaian } \\
\text { yang } \\
\text { tersedia di }\end{array}$ \\
\hline
\end{tabular}

Johnson Sihombing, Lamhot Sihotang 


\begin{tabular}{l}
\hline \hline Kesimpulan : \\
\hline \hline \multicolumn{1}{c|}{ perusahaan } \\
\hline \hline $\begin{array}{l}\text { Dengan dibuatnya website ini, perusahaan dapat } \\
\text { memperluas zona pemasaran produk. } \\
\text { Apikasi berbasis website menyajikan informasi kategori } \\
\text { produk pakaian yang dapat dipesan oleh pelanggan } \\
\text { Aplikasi berbasis website dapat diakses oleh pelanggan } \\
\text { dimana saja dan kapanpun }\end{array}$ \\
\hline \hline
\end{tabular}

\section{Metodologi Penelitian}

Dalam kegiatan analisis dan perancangan sistem, penulis memilih untuk menggunakan metode RUP, yang terdiri atas beberapa tahapan proses : business modelling (pemdoelan bisnis), software requirements specification (kebutuhan pengumpulan), analysis and design (analisa dan desain), testing and implementation (pengujjian dan implementasi).

\section{III.1 Business Modelling}

Kegiatan business modelling dimulai dengan melakukan wawancara dengan pihak PT. Tegar Primanusantara Cimahi, antara lain wawancara dengan staf Marketing, Supervisor Marketing, Manager Marketing dan Manager Perusahaan. Setelah proses wawancara selesai dilaksanakan, maka didapatkan hasil berupa diagram aktivitas dari PT. Tegar Primanusantara seperti di bawah ini :

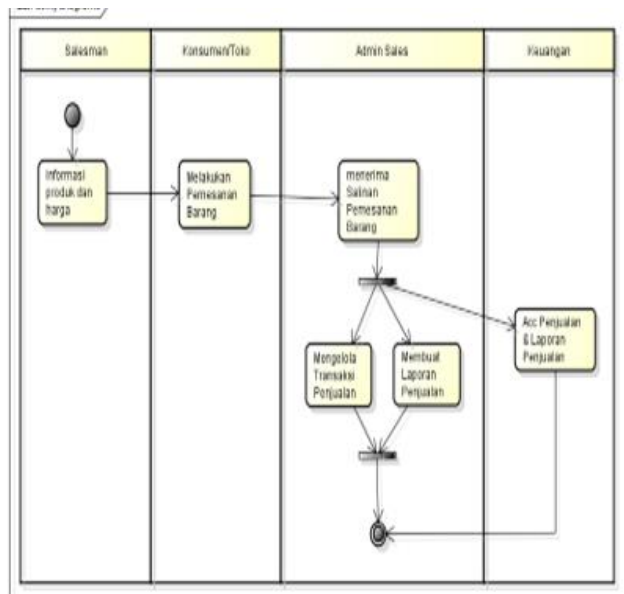

Gambar 1 Diagram aktivitas yang sedang berjalan

\section{III.2 Sofware Requirements Specification}

Pengumpulan kebutuhan perangkat untuk membangun sistem ini terdiri atas kebutuhan fungsional dan kebutuhan non-fungsional.

Tabel 2 Kebutuhan Fungsional

\begin{tabular}{cll}
\hline \hline No. & $\begin{array}{l}\text { Kebutuhan } \\
\text { Fungsional }\end{array}$ & Aktor \\
\hline \hline & $\begin{array}{l}\text { Sistem melakukan } \\
\text { login terlebih dahulu } \\
\text { sebelum dapat di } \\
\text { akses }\end{array}$ & $\begin{array}{l}\text { Admin Sales } \\
\text { memasukkan username } \\
\text { dan password }\end{array}$ \\
\hline \hline & $\begin{array}{l}\text { Sistem mencatat } \\
\text { order pesanan dari } \\
\text { pelanggan }\end{array}$ & $\begin{array}{l}\text { Admin } \text { Sales } \text { melakukan } \\
\text { input pesanan pelanggan }\end{array}$ \\
\hline \hline & $\begin{array}{l}\text { Sistem harus mampu } \\
\text { menyimpan data } \\
\text { pesanan pelanggan }\end{array}$ & $\begin{array}{l}\text { Admin } \text { Sales menyimpan } \\
\text { data barang pesanan } \\
\text { pelanggang }\end{array}$ \\
\hline \hline & $\begin{array}{l}\text { Sistem membuat } \\
\text { laporan rekapitulasi } \\
\text { penjualan }\end{array}$ & $\begin{array}{l}\text { Manager Perusahaan } \\
\text { mengecek dan } \\
\text { menyetujui laporan } \\
\text { secara berkala }\end{array}$ \\
\hline \hline
\end{tabular}

Tabel 3 Kebutuhan Non-Fungsional

\begin{tabular}{|c|c|c|c|}
\hline No. & $\begin{array}{l}\text { Kebutuhan } \\
\text { Fungsional }\end{array}$ & Non- & Keterangan \\
\hline 1 & Operasional & & $\begin{array}{l}\text { Windows } 7 \text { Ultimate } 64 \\
\text { bit; Processor (Intel } 1.33 \\
\text { Ghz), RAM : 2/00 GB, } \\
\text { VGA : 256 MB, Monitor: } \\
\text { 14' inch, Web Browser } \\
\text { : Mozilla Firefox; Web } \\
\text { Server: } \\
\text { Database Apache; } \\
\text { MySQL; Sublime Teks } \\
\text { 3; XAMPP versi } 1.7 .3 \\
\text { dengan } \\
\text { PhpMySQL. }\end{array}$ \\
\hline 2 & Keamanan & & $\begin{array}{lr}\text { Aplikasi dan } & \text { database di } \\
\text { proteksi } & \text { dengan } \\
\text { password; n } & \text { berikut } \\
\text { perangkat } & \text { CCTV di } \\
\text { kantor } & \end{array}$ \\
\hline 3 & Informasi & & $\begin{array}{l}\text { Menyajikan informasi } \\
\text { berupa pmesanan produk }\end{array}$ \\
\hline
\end{tabular}




\section{III.3 Analisis dan Desain}

Pada taap ini, penulis menggunakan diagram use case untuk mendeskripsikan kegiatan-kegiatan yang terdiri dari user, interaksi user-sistem dan interaksi antar user. Adapun penggunaan diagram use case ini adalah untuk mengetahui komponen-komponen yang digunakan dalam sistem dan user accessability. Bentuk diagram use case untuk sistem informasi penjualan perlengkapan rumah tangga berbasis web di PT. Tegar Primanusantara Cimahi adalah sebagai berikut :

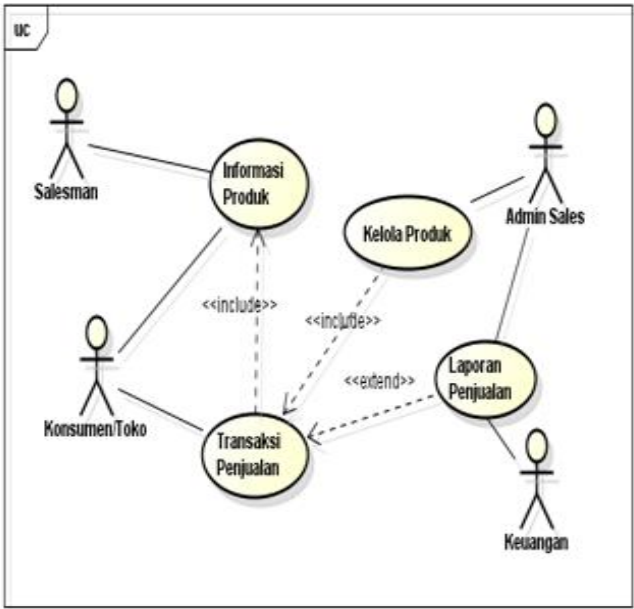

Gambar 2 Class Diagram

Sedangkan struktur data yang digunakan pada sistem informasi penjualan perlengkapan rumah tangga berbasis web di PT. Tegar Primanusantara dapat dilihat dibawah ini :

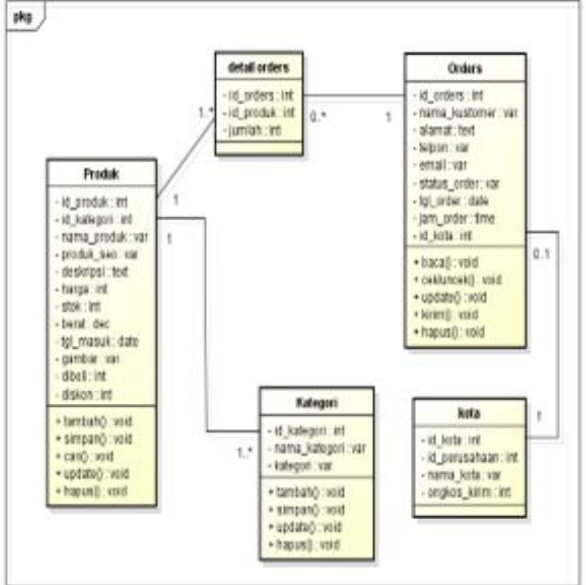

Gambar 3 Class Diagram

\section{III.4 Implementasi Sistem}

Kegiatan pada tahap iini akan menguraikan hasil dari penelitian sistem informasi penjualan perlengkapan rumah tangga berbasis web di PT. Tegar Primanusantara Cimahi. Gambar berikut menampilkan tampilan awal sistem yang berbentuk Form Login Login screen). Caranya : buka aplikasi Sistem Informasi penjualan perlengkapan rumah tangga berbasis web dan klik menu Login.

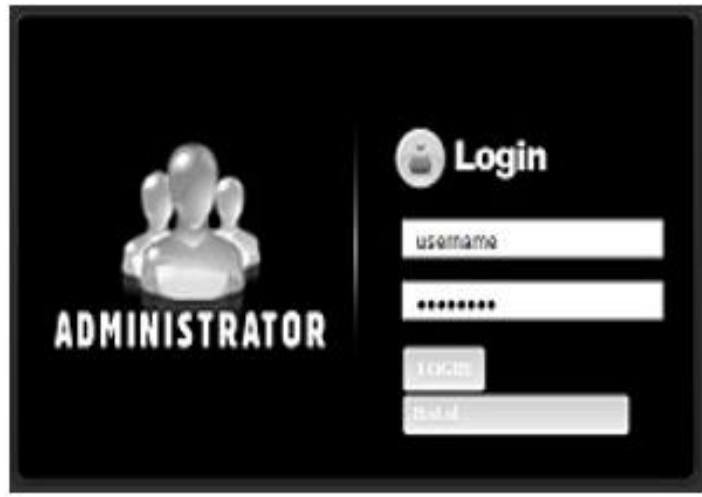

Gambar 4 Dialog Screen Login

Setelah user melakukan login, maka akan truktuinformasi penjualan perlengkapan rumah tangga PT. Tegar Primanusantara sebagai berikut :

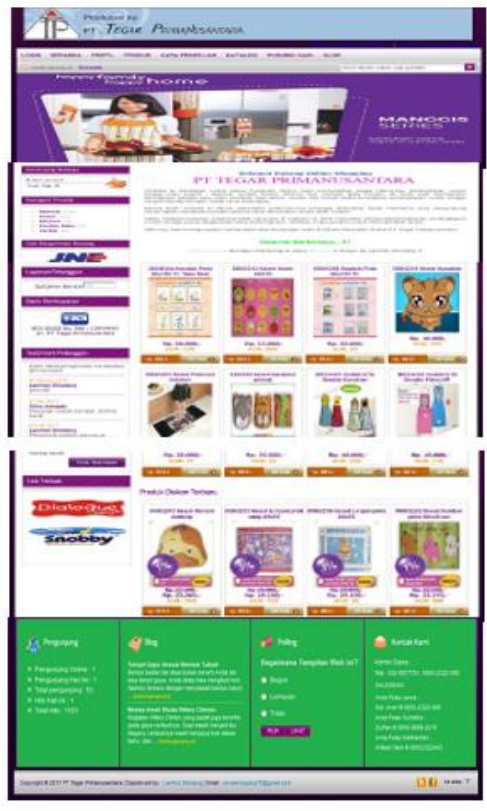

Gambar 5 Halaman utama website 
Pada menu Administrator, ada beberapa submenu yang bisa di akses dengan ikon-ikon menu Administrator yang sudah tersedia :

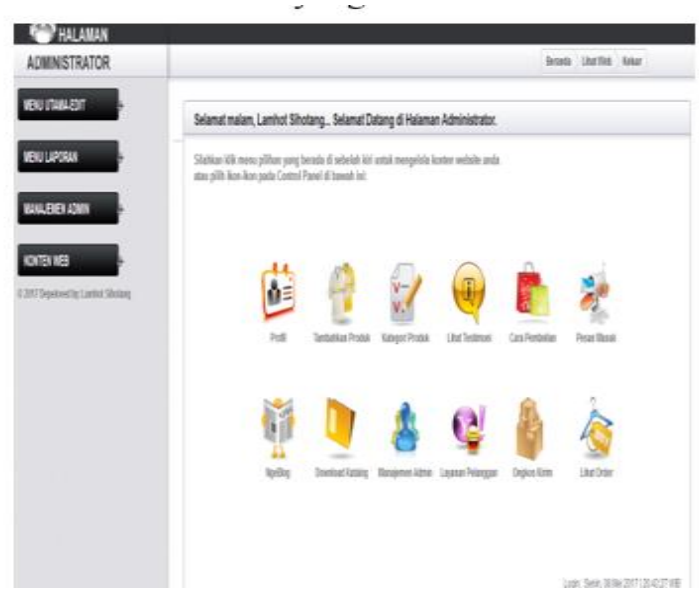

Gambar 6 Menu Administrator

Pada menu Produk ada sub menu Edit Produk dan Order Masuk. Pada sub menu Edit Produk dengan tampilan sebagai berikut :

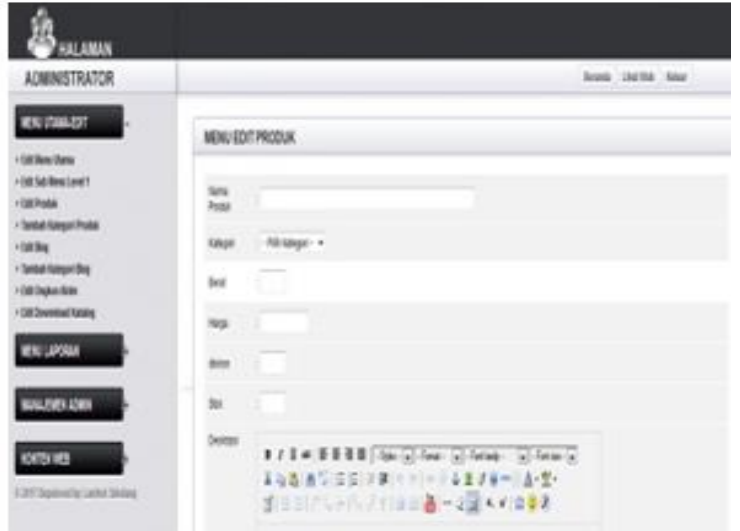

Gambar 7 Menu edit produk

Setelah pelanggan memesan produk, maka dapat terlihat produk-produk yang sudah dipesan para pelanggan :

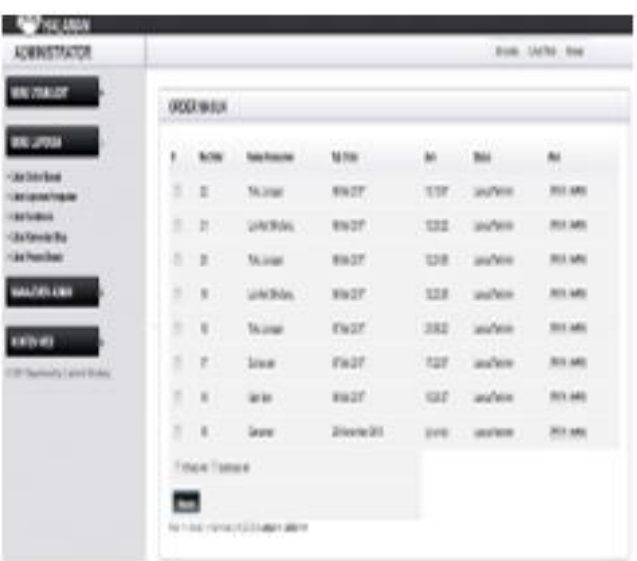

Gambar 8 Daftar order masuk

Pada menu menu Laporan, terdapat dua pilihan laporan, yaitu : Laporan Penjualan Harian dan Laproan Penjualan Periodik seperti berikut ini :

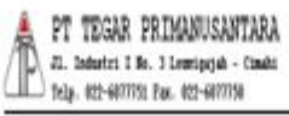

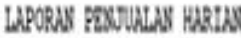

\begin{tabular}{|c|c|c|c|c|}
\hline b fiatur & 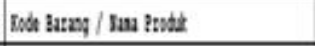 & itg & $\operatorname{sarp}$ & Sid satal. \\
\hline 1. 13 & 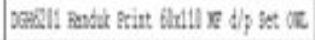 & 11 & 10.000,- & $1.12000000_{-}^{-}$ \\
\hline $2 \cdot 21$ & 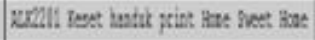 & ? & 2.00. & 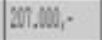 \\
\hline 321 & 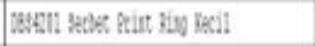 & & s.m. & $15,100,-$ \\
\hline 422 & 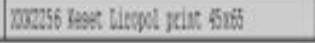 & (4) & $30,000$. & 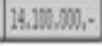 \\
\hline
\end{tabular}

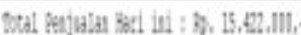

Jald yey tet)al : 4 uit

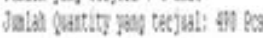

Gambar 9 Laporan penjualan harian 


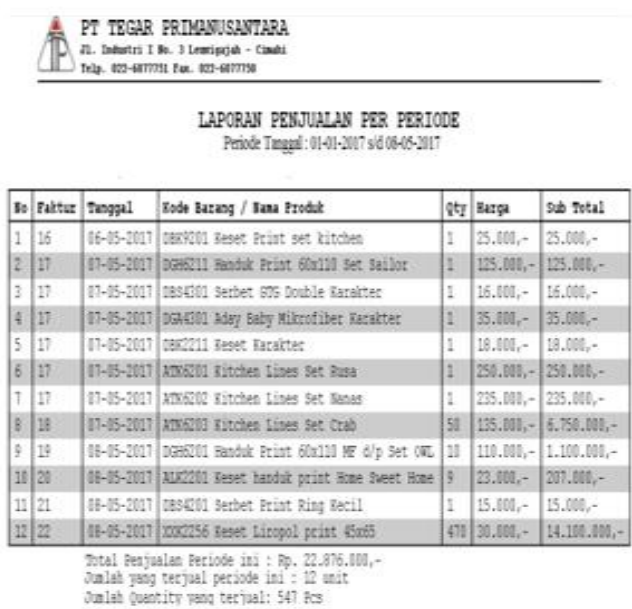

Gambar 10 Laporan penjualan secara periodik

\section{Analisis dan Perancangan}

\section{IV.1 Hasil Pengujian}

Untuk tahap pengujian sistem informasi penjualan perlengkapan rumah tangga berbasis web ini, penulis menggunakan metode Black Box testing, yaitu proses pengujian fungsi-fungsi perangkat lunak yang ada pada sistem berjalan. Proses Peengujian sistem ini merupakan alah satu syarat yang harus dilasanakan dan dipenuhi dalam membangun sistem informasi.

Tester yang berperan sebagai penguji fungsi terhadap perangkat lunak akan menemukan kondisikondisi input yang digunakan untuk memenuhi persyaratan fungsional dari aplikasi seperti berikut ini

1. Fungsi-fungsi yang masih belum lengkap

2. Ketidak sesuaia antar muka

3. Struktur data tidak cocok atau akses terhadap basis data eksternal

4. Inisialisasi dan kesalahan terminasi

5. fungsional yang belum valid

6. Pengunaan nilai/format input tertentu yang tidak sesuai dengan sistem

7. Salah input nama field dari satu atau beberapa file dari suatu database

Adapun pengujian perangkat lunak pengolahan data penjualan ini sebagai berikut :
Tabel 4 Hasil Pengujian

\begin{tabular}{|c|c|c|c|c|c|}
\hline $\begin{array}{c}\text { Kelas } \\
\text { Cji }\end{array}$ & $\begin{array}{l}\text { Skenario } \\
\text { Pengujian }\end{array}$ & \multicolumn{2}{|c|}{$\begin{array}{l}\text { Hasil Yang } \\
\text { Diharapkan }\end{array}$} & \multicolumn{2}{|c|}{ Hasil Pengujian } \\
\hline Login & $\begin{array}{l}\text { Ketikkan usemame } \\
\text { dan password, } \\
\text { kemudian klik } \\
\text { button Login }\end{array}$ & $\begin{array}{l}\text { Memu } \\
\text { Admin } \\
\text { ditamp } \\
\text { userna } \\
\text { passuo }\end{array}$ & $\begin{array}{l}\text { Halaman } \\
\text { istrator } \\
\text { ltkan jika } \\
\text { me dan } \\
\text { rd sesuai }\end{array}$ & & Sesuai \\
\hline Kolas $\mathrm{CJj}^{\mathrm{j}}$ & Skenario Pengo & & $\begin{array}{l}\text { Hasil Y } \\
\text { Dlasara }\end{array}$ & & $\begin{array}{c}\text { Hasil } \\
\text { Peagujian }\end{array}$ \\
\hline $\begin{array}{l}\text { CaniData } \\
\text { Prodak }\end{array}$ & $\begin{array}{l}\text { Masukkan nama } \\
\text { pada tertbor cari } \\
\text { kenudón klik buto }\end{array}$ & $\begin{array}{l}\text { produk } \\
\text { i data } \\
\text { on cari }\end{array}$ & $\begin{array}{l}\text { Data yan } \\
\text { akan mus } \\
\text { datagridri }\end{array}$ & $\begin{array}{l}\text { dicari } \\
\text { ul di } \\
\text { a }\end{array}$ & Sesuai \\
\hline $\begin{array}{l}\text { EditData } \\
\text { Produk }\end{array}$ & $\begin{array}{l}\text { Klik button edit pac } \\
\text { Produk yang akan } \\
\text { maka akan muncul } \\
\text { dara produk } \\
\text { masing terisi pada } \\
\text { dan comboborken } \\
\text { ubabdatayang din } \\
\text { kemudon klik } \\
\text { update sehingga } \\
\text { produk yang } \\
\text { berubah. }\end{array}$ & $\begin{array}{l}\text { da data } \\
\text { didit } \\
\text { i data. } \\
\text { masing } \\
\text { tertbor } \\
\text { mudian } \\
\text { iginkan } \\
\text { buthon } \\
\text { data } \\
\text { diedit }\end{array}$ & $\begin{array}{l}\text { Dataprod } \\
\text { diedit ben } \\
\text { database }\end{array}$ & $\begin{array}{l}\text { kyang } \\
\text { oal di }\end{array}$ & Sesuad \\
\hline
\end{tabular}

\begin{tabular}{|c|c|c|c|}
\hline $\begin{array}{l}\text { Hapus Data } \\
\text { Prodik }\end{array}$ & $\begin{array}{l}\text { Pilih produk yang akan } \\
\text { dihapus dengan klik button } \\
\text { hapus maka data akan } \\
\text { terhapus sesuai dengan } \\
\text { yang dinginkan. }\end{array}$ & $\begin{array}{l}\text { Data yang } \\
\text { dihapus hilang } \\
\text { dari dotabose }\end{array}$ & Sesuai \\
\hline $\begin{array}{l}\text { Batal Data } \\
\text { Produk }\end{array}$ & $\begin{array}{l}\text { Masukkan data pada } \\
\text { masing-masing textbox } \\
\text { atau combobox kemudian } \\
\text { klik button batal maka data } \\
\text { yang yang ada di textbox } \\
\text { ataupun combobox akan } \\
\text { hilang }\end{array}$ & $\begin{array}{l}\text { Data-data yang } \\
\text { dimastikkan pada } \\
\text { textbox maupun } \\
\text { combobox } \\
\text { menghilang }\end{array}$ & Sesuai \\
\hline $\begin{array}{l}\text { Tambah } \\
\text { Data } \\
\text { Produk }\end{array}$ & $\begin{array}{l}\text { Klik button Tambah } \\
\text { Produk maka akan } \\
\text { muncul data-data produk } \\
\text { masing masing terisi pada } \\
\text { tectbor rerpun } \\
\text { combobox kemudian } \\
\text { simpan data yang yang } \\
\text { dimput kemudian klik } \\
\text { burton simpan sehingga } \\
\text { data produk akan } \\
\text { tersimpan. }\end{array}$ & $\begin{array}{l}\text { Data Produk } \\
\text { yang diedit akan } \\
\text { bertambah } \\
\text { didatabase }\end{array}$ & Sesuai \\
\hline $\begin{array}{l}\text { Browse. } \\
\text { gambar } \\
\text { Produk }\end{array}$ & $\begin{array}{l}\text { Pada saat menambahkan } \\
\text { atau edit produk Klik } \\
\text { buttonbrowse maka akan } \\
\text { mencari file yang ber- } \\
\text { extensi jpg data produk }\end{array}$ & $\begin{array}{lr}\text { Gambar } & \text { Produk } \\
\text { akan diupload ke } \\
\text { database } & \text { dan } \\
\text { bertambah } & \text { di } \\
\text { database. } & \end{array}$ & Sesuai \\
\hline
\end{tabular}




\section{KESIMPULAN DAN SARAN}

\section{V.1 Kesimpulan}

Dari penjabaran-penjabaran yang telah penulis lakaukan di atas, penulis membuat beberapa kesimpulan seperti berikut ini :

1. Aplikasi berbasis web ini berdungsi sebagai media informasi bagi produk-produk yang dapat dilihat dan dipersan oleh pelanggan.

2. Sistem informasi penjualan perlengkapan rumah tangga berbasis web ini memudahkan pihak perusahaan untuk mengeloh data penjualan produk.

3. Memudahkan sistem pengolahan data customer/pelanggan (baik secara korporasi maupun individu), stok produk, dan transaksi penjualan prodeu..

4. Perancangan sistem informasi penjualan perlengkapan rumah tangga berbasis web pada perusahaan ini memberi kemudahan dalam proses pemesana dan penjualan produk.

Aplikasi berbasis web ini dirasakan belum sempurna dan masih harus dilakukan pengembangan di beberapa elemen/fungsi agar menjadi suatu sistem informasi yang terintegrasi. Ada beberaa saran yang penulis lakukan untuk tahap pengembangan berikutnya

1. Membuat sub menu khusus untuk pembayaran secara online atau sistem paypal.

2. Menambahkan fitur pemesanan produk

3. penjualan perlengkapan rumah tangga.

4. Menambahkan fitur untuk penghitungan keuntungan/

\section{REFERENSI}

Romeo. (2003). Testing dan Implementasi Sistem. Surabaya: STIKOM Surabaya

Hetzel, B. (1998). The Complete Guide to Software Testing Second Edition. New York: John Wiley \& Sons.

Mulyan, Sri. (2016). Metode Analisis dan Perancangan Sistem. Edisi Kedua. Cetakan ke-1. Bandung : Abdi Sistematika

Sumarsono. (2010). Dasar-dasar Penjualan. Jakarta : PT. Elex Media Komputindo
Prakoso, Nicon. (2014). Perancangan Sistem Informasi Toko Online Andriano Mx Shop Purworejo Berbasis Website Dengan Codeigniter dan Bootstrap. Naskah skripsi jurusan Sistem Informasi STMIK AMIKOM Yogyakarta.

Hasanah, Uswatun. (2013). Sistem Informasi Penjualan Online Pada Toko Kreatif Suncom Pacitan. Indonesian Journal on Networking and Security. Volume 2.

Novaliedry, Dony and Sriwahyuni Arrum Pramesti, Titi. (2014). Perancangan Website E-commerce Express Order System For Reseller. Jurnal Vokasional Teknik Elektro dan Informatika. Volume 2.

Kasali, Rhenald. (2007). Membidik Pasar Indonesia Segmentasi targeting Positioning. Jakarta: PT Gramedia utama

Triady, Muh Masri. (2012). Analisis Pengaruh Strategi Bauran Promosi Terhadap Peningkatan Volume Penjualan Pada Produk Jasa (Studi Produk TAMPAN pada PT. Bank Sulselbar Cab Utama) 